\title{
Evaluation of the Effect of Radiofrequency Denervation on Quality of Life of Patients with Facet Joint Syndrome by Oswestry Disability Index Score and Visual Analogue Scale Score
}

\section{Zafer Gündoğdu', Mesut Öterkuş ${ }^{2}$, Ümit Karatepe ${ }^{3}$}

${ }^{1}$ Department of Anaesthesiology and Reanimation, Elazığ Medical Park Hospital, Elazığ, Turkey;

${ }^{2}$ Department of Anaesthesiology and Reanimation, Faculty of Medicine, Malatya Turgut Özal University, Malatya, Turkey;

${ }^{3}$ Department of Anaesthesiology and Reanimation, Elazığ Fethi Sekin City Hospital, Elazı̆̆, Turkey

Received April 13, 2021; Accepted October 20, 2021.

Key words: Low back pain - Lumbar facet joint syndrome - Radiofrequency denervation

Abstract: In this study, we aimed to investigate the effect of radiofrequency denervation procedure on pain and quality of life of patients with facet joint syndrome. Forty-seven patients who were admitted to our hospital with low back pain and diagnosed with facet joint syndrome between January 2018 and December 2018 were included in our study. The patients underwent denervation with radiofrequency under fluoroscopy in a sterile operating room condition. The preprocedure and $6^{\text {th }}$ month follow-up VAS (visual analogue scale) and ODI (Oswestry disability index) scores of the patients were recorded. When the demographic data of the patients were analysed, the mean age of the patients was found to be 52 . Of the patients, $61.7 \%$ were female. In the evaluation of VAS and ODI scores, which we used to measure the efficiency of the procedure, the $6^{\text {th }}$ month values were found to be statistically lower than the pre-procedure values $(p<0.05)$. The first treatment for

Mailing Address: Mesut Öterkuş, MD., Department of Anaesthesiology and Reanimation, Faculty of Medicine, Malatya Turgut Özal University, Alacakapı Mahallesi Kırkgöz Caddesi No:70 P.K., 44210 Battalgazi, Malatya, Turkey; Phone: +905 438550 954; e-mail: mesutoterkus@hotmail.com 
facet joint syndrome is bed rest and medical treatment. Resistant cases also benefit from physical therapy and intra-articular steroid injection. In patients unresponsive to these treatments, denervation with radiofrequency appears to be an effective method. At least two levels must be performed for the procedure to be successful. Studies have shown that pain decreases in the long term (6-12 months) and quality of life increases. We also obtained similar results in our studies. In conclusion, we think that RF (radiofrequency) can be used as an effective method in cases where other treatments fail.

\section{Introduction}

It is possible to define chronic pain as a condition that is resistant to administered treatment regimens, requires long-term treatment, and affects the quality of life of individuals in all fields. This constant pain restricts the simplest movements of individuals and causes difficulties in both work and daily life. This leads to anxiety and depression. Most of these pains are low back and leg pain. Although the most common cause is lumbar disc herniation, studies have shown that $15-40 \%$ of low back pain is caused by facet joint pain (Al-Najjim et al., 2017). The pain originates from the median branch of the spinal dorsal ramus (McCormick et al., 2014; Al-Najjim et al., 2017). Medical treatment (analgesics, anti-inflammatory drugs, muscle relaxants and antidepressants, etc.) and bed rest are given as treatment. If pain persists, physical therapy and/or surgical therapy is another treatment option. In treatment-resistant persistent cases, invasive procedures such as radiofrequency (RF), steroid and/or local anesthesia can be used for the treatment (Bogduk, 2005).

Facet joint denervation with radiofrequency is used as a treatment option in resistant cases (Schwarzer et al., 1994). It was first used in 1973 by Dr. Shealy. Radiofrequency denervation aims to prevent the transmission of nonspecific stimuli by damaging the nerve that transmits pain. If the local anesthetic injection temporarily relieves the pain, RF will be beneficial. With radiofrequency, a clinical improvement is observed in pain lasting 6-12 months (Shabat et al., 2013). Today, quite successful results can be obtained with the development of radiological imaging examinations.

\section{Material and Methods}

In this retrospective clinical study, 47 patients between the ages of 18-75 who were diagnosed with facet syndrome and underwent facet denervation among the patients who were admitted to the Algology Outpatient Clinic of Elazig Fethi Sekin City Hospital between January 2018 and December 2018 after the ethics committee approval was obtained. The sample size was calculated with reference to previous studies. Alpha error of 0.05 was accepted as beta error 0.8 , and the minimum sample size was calculated as 44 patients. Firat University non-invasive studies were approved by the ethics committee dated 14.01.2021 and numbered 2021/01-28. 
Patients requiring surgical treatment, those who were pregnant or were suspected pregnancy, patients younger than 18 years of age, patients with coagulation disorder, patients with local or systemic infectious disease were excluded from the study.

Patients who were scheduled for denervation procedure with RF due to lumbar facet joint syndrome were transferred to the operating room. After the diagnostic block was performed with local anesthetic (1 cc, $2 \%$ lidocaine) under fluoroscopy, the patients who benefited from the block $50 \%$ or more underwent denervation with RF. All patients underwent denervation procedure with conventional RF under fluoroscopy using a 17 G C-RFA electrode (Lumbar Cool [R] Cooled Radiofrequency Kit, Kimberly-Clark, LLC, Roswell, GA) for 90 seconds at 80 degrees by finding the target nerve at L1-5 levels. The patients were discharged with recommendations (not using cars and tools requiring manual skills for 24 hours, etc.) after the observation in the ward for a few hours after the procedure.

Age, gender, trauma history (present-absent), previous treatments received (medication, physical therapy, radiofrequency treatment), pre-treatment visual analogue scale (VAS) scores and Oswestry disability index (ODI) were recorded. The VAS and ODI scores of the patients were recorded again in the $6^{\text {th }}$ month after the procedure in order to evaluate the success of the procedure.

\section{Statistical analysis}

Number (n) and percentage (\%) values were used to show the distribution of individuals and demographic information such as gender, hypertension and diabetes. The normality distribution of continuous variables such as age, height, weight, preVAS score, post-VAS score, pre-ODI score, post-ODI score in the study were evaluated graphically by the Shapiro-Wilks test. The median (IR - interquartile range) values were used to show descriptive statistics. Additionally, mean \pm standard deviation values were used for descriptive statistics. The paired sample paired twosample $t$-test $(\mathrm{t})$ was used to compare pre-ODI score and post-ODI score values. In addition, the Wilcoxon signed-rank test was used to compare pre-VAS score and post-VAS score values. The Wilcoxon signed-rank test $(Z)$ was used to compare the pre- and post-values of the ODI score sub-dimensions (pain intensity, personal care, lifting, etc.). IBM SPSS Statistics Version 21.0 (IBM Corp. Released 2012; IBM SPSS Statistics for Windows, Version 21.0, Armonk, NY) and MS-Excel 2007 software were used for statistical analysis and calculations. The level of statistical significance was accepted as $\mathrm{p}<0.05$.

\section{Results}

Of the individuals participating in the study, 38.3\% $(n=18)$ were male and $61.7 \%(n=29)$ were female. The mean age of the individuals was determined as $52.16 \pm 12.67$ years. In addition, it was determined that the mean height of the individuals was $164.77 \pm 9.38 \mathrm{~cm}$ and the mean weight was $75.43 \pm 13.89 \mathrm{~kg}$ (Table 1). 


\section{Table 1 - Descriptive statistics}

\begin{tabular}{lcc}
\hline & Mean \pm SD & Median (IR) \\
\hline Age & $52.16 \pm 12.67$ & $55.0(16.0)$ \\
Height & $164.77 \pm 9.38$ & $165.0(14.0)$ \\
Weight & $75.43 \pm 13.89$ & $73.0(23.0)$ \\
pre-VAS & $7.04 \pm 1.30$ & $7.0(2.0)$ \\
post-VAS & $3.78 \pm 0.92$ & $4.0(1.0)$ \\
pre-ODI & $46.24 \pm 17.54$ & $46.0(22.0)$ \\
post-ODI & $21.56 \pm 7.35$ & $22.0(11.0)$ \\
\hline
\end{tabular}

VAS - visual analogue scale; ODI - Oswestry disability index; SD - standard deviation; IR - interquartile range

Table 2 - Comparison of pre- and post-procedure VAS values

\begin{tabular}{lccc}
\hline pre-VAS & post-VAS & \multicolumn{2}{c}{ Test statistics } \\
\hline Median (IR) & Median (IR) & Z & P \\
\hline $7.0(2.0)$ & $4.0(1.0)$ & 5.974 & $<0.001$ \\
\hline
\end{tabular}

VAS - visual analogue scale; IR - interquartile range; $Z$ - Wilcoxon signed-rank test statistics

Table 3 - Comparison of pre- and post-procedure ODI values

\begin{tabular}{lccc}
\hline pre-ODI & post-ODI & \multicolumn{3}{c}{ Test statistics } \\
\hline Mean \pm SD & Mean \pm SD & t & P \\
\hline $46.24 \pm 17.54$ & $21.56 \pm 7.35$ & 13.294 & $<0.001$ \\
\hline
\end{tabular}

ODI - Oswestry disability index; SD - standard deviation; $\mathrm{t}$ - paired two-sample $t$-test

It was found that the individuals showed a statistically significant difference in the comparison of the pre-procedure VAS values and post-procedure VAS values $(Z=5.974 ; p<0.001)$. It was determined that the median pre-procedure VAS value was higher than the median post-procedure VAS value (Table 2).

A statistically significant difference was found in the comparison of the preprocedure ODI values and the post-procedure ODI values $(t=13.294 ; p<0.001)$. It was found that the mean pre-procedure ODI values of the individuals were higher than the mean post-procedure ODI values (Table 3).

A statistically significant difference was found in the comparison of the pre- and post-pain intensity values of the individuals participating in the study $(Z=5.809$, $p<0.001)$. The pre-procedure median value of the pain intensity of the individuals was determined as $3.0(I R=1.0)$ and the post-procedure median value was 1.0 $(I R=0.0)$ (Table 4). The comparison of other parameters is summarized in Table 4. 
Table 4 - Comparison of pre- and post-values of the parameters

\begin{tabular}{lcccc}
\hline & $\begin{array}{c}\text { Pre-median } \\
\text { (IR) }\end{array}$ & $\begin{array}{c}\text { Post-median } \\
\text { (IR) }\end{array}$ & \multicolumn{2}{c}{ Test statistics } \\
\cline { 4 - 5 } & $3.0(1.0)$ & $1.0(0.0)$ & $\mathbf{Z}$ & $\mathbf{p}$ \\
\hline Pain intensity & $1.0(2.0)$ & $1.0(1.0)$ & 3.809 & $<0.001$ \\
Personal care & $1.0(1.0)$ & 5.010 & $<0.001$ \\
Lifting heavy & $3.0(4.0)$ & $1.0(0.0)$ & 5.566 & $<0.001$ \\
Walking & $3.0(1.0)$ & $1.0(0.0)$ & 5.311 & $<0.001$ \\
Sitting & $3.0(2.0)$ & $1.0(1.0)$ & 5.737 & $<0.001$ \\
Standing up & $3.0(2.0)$ & $1.0(1.0)$ & 4.755 & $<0.001$ \\
Sleep & $2.0(3.0)$ & $1.0(1.0)$ & 2.658 & 0.001 \\
Sexual life & $1.0(1.0)$ & $1.0(0.0)$ & 4.336 & $<0.001$ \\
Social life & $1.0(3.0)$ & $1.0(0.0)$ & 5.261 & $<0.001$ \\
Travel & $2.0(2.0)$ & & &
\end{tabular}

IR - interquartile range; $Z$ - Wilcoxon signed-rank test statistics

\section{Discussion}

The facet joints in the lumbar region have an important role in the movement and stabilization of the spine (Hägg and Wallner, 1990; Acarkan et al., 2019). They also play an important role in carrying body weight (Beyazova and Gökçe Kutsal, 2000). The fibers of the medial branch of the posterior primary ramus and the dorsal branch of the sinovertebral nerve provide innervation of the facet joints. The pain originates from the medial branch located at the same level and the medial branch originating from the upper segment. It is pain in the form of back pain may radiate to the side of groin, thigh or knee.

Lumbar facet syndrome occurs as back pain or sciatic pain due to facet joint degeneration due to aging, traumatic, etc. (Maas et al., 2015). Patients present with pain that increases with movement (bending back and side). Pain spreads to regions such as hips, thighs and knees. There is pain with palpation of the facet joint. Patients complain of a blunt pain. Hypertrophy of the facet joints, synovial cysts and irregularities in the joint surfaces can be visualized radiologically. In the examination, the straight leg raise test is negative. Diagnostic blocks the facet joints and nerves that innervate these joints with local anesthetics make a diagnosis; however, this is not a 100\% reliable method (Cohen and Raja, 2007). The first-line treatment is bed rest and medication (non-steroidal anti-inflammatory drugs - NSAIDs, myorelaxants, antidepressants, opioids, etc.). Physical therapy is added to the treatment in unresponsive patients. Cases resistant to conservative treatment benefit from the injections of local anesthetic and steroid into the facet joint (Cohen and Raja, 2007; Çırak and Çağlar Okur, 2020). Denervation is performed with RF in cases that do not respond to current treatments. At least two levels of denervation should be performed, since the facet joints are innervated from the medial branches at the same level and the upper one. The effectiveness of surgery in facet joint syndrome is controversial (Manchikanti et al., 2000). 
There are two different types of RF, namely conventional RF used for procedures such as facet joint denervation, and pulsed RF used for conditions such as chronic neuropathy and peripheral neuropathies. In conventional practice, heat ablation is provided by stimulation with continuous heat dissipation from a needle catheter (Cohen and Raja, 2007; Vatansever et al., 2008). Before the procedure, the medial branches of the facet joint should be locally anesthetized under fluoroscopy and under sterile conditions and it should be observed that more than $50 \%$ relief is achieved in pain. This procedure is diagnostic. After this procedure, conventional $\mathrm{RF}$ is performed at $80^{\circ} \mathrm{C}$ for $60-120$ seconds. In our study, we completed the denervation procedure by applying RF at $80^{\circ} \mathrm{C}$ for 90 seconds.

Tekin et al. (2007) compared the efficacy of pulsed RF and conventional RF methods in chronic facet joint pain and evaluated patients' VAS and IR values before the procedure, 6 months and 1 year after the procedure. As a result, they reported that both pulsed RF and conventional RF methods were effective in reducing pain and could be an alternative method in treatment. However, they concluded that conventional RF was more effective than pulsed RF, and the number of patients not using analgesics and patient satisfaction were higher in conventional RF (Tekin et al., 2007).

Studies have shown that patients' back pain increases from the age of 35 and this increase continues until the age of 50s (Nagi, 1976). The reason for this increase can be attributed to the fact that patients are more physically active and therefore more exposed to factors such as trauma. In our study, we found the mean age of the patients as 52 .

Studies have found that low back pain is more common in housewives (Stranjalis et al., 2004). Similarly, the study by Nagi (1976) found that females had more back pain than males. Similarly, we found that it was more common in females (61.7\%). This difference can be explained by the fact that women are more susceptible to trauma, they do more housework, express their existing complaints more and by hormonal changes due to menstruation.

Studies have shown long-term (6-12 months) improvement in patients after denervation with RF. In a meta-analysis studies conducted by Lee et al. (2017), VAS values were found to be significantly better in the RF group at 12-month follow-up compared to the control group. Similarly, in another cohort study performed, significant improvements were observed in patients at 12 months in denervation with RF (Dreyfuss et al., 2000).

In our study, we examined the VAS and ODI scores to evaluate the effectiveness of the treatment and the effect of the procedure on the quality of life. We found a significant decrease in VAS values at the post-procedure 6-month follow-ups. In the analysis of the ODI score values, in which the patients' deteriorated quality of life (sleep, social life, walking, etc.) by pain was evaluated, it was found that there was a significant increase in the quality of life due to the post-procedure decrease in pain. 


\section{Conclusion}

We think that in cases resistant to other treatment options, denervation with RF provides significant relief in the pain levels of the patients and increases the quality of life.

\section{References}

Acarkan, T., Elmacıoğlu, M., Nazlıkul, H. (2019) Facet joint syndrome and clinical reflections. J. Complement. Med. Regul. Neural Ther. 13(1), 8-13. (in Turkish)

Al-Najjim, M., Shah, R., Rahuma, M., Gabbar, O. A. (2017) Lumbar facet joint injection in treating low back pain: Radiofrequency denervation versus SHAM procedure. Systematic review. J. Orthop. 15(1), 1-8.

Beyazova, M., Gökçe Kutsal, Y. (2000) Physical Medicine and Rehabilitation. Physical Properties and Functional Biomechanics of the Lumbar Spine. M. Karataş Güneş Bookstore, Ankara.

Bogduk, N. (2005) A narrative review of intra-articular corticosteroid injections for low back pain. Pain Med. 6, 287-296.

Çırak, M., Çağlar Okur, S. (2020) Does ultrasound-guided facet joint injection reduce pain and improve mobility in patients with failed back surgery syndrome? Jt. Dis. Relat. Surg. 31(3), 564-570.

Cohen, S. P., Raja, S. N. (2007) Pathogenesis, diagnosis, and treatment of lumbar zygapophysial (facet) joint pain. Anesthesiology 106(3), 591-614.

Dreyfuss, P., Halbrook, B., Pauza, K., Joshi, A., McLarty, J., Bogduk, N. (2000) Efficacy and validity of radiofrequency neurotomy for chronic lumbar zygapophysial joint pain. Spine (Phila. Pa 1976) 25(10), 1270-1277.

Hägg, O., Wallner, A. (1990) Facet joint asymmetry and protrusion of the intervertebral disc. Spine (Phila. Pa 1976) 15(5), 356-359.

Lee, C. H., Chung, C. K., Kim, C. H. (2017) The efficacy of conventional radiofrequency denervation in patients with chronic low back pain originating from the facet joints: A meta-analysis of randomized controlled trials. Spine J. 17(11), 1770-1780.

Maas, E. T., Osteol, R. W., Niemistol, L., Jousimaa, J., Hurri, H., Malmivaara, A., van Tulder, M. W. (2015) Radiofrequency denervation for chronic low back pain. Cochrane Database Syst. Rev. 10, CD008572.

Manchikanti, L., Pampati, V., Fellows, B., Baha, A. G. (2000) The inability of the clinical picture to characterize pain from facet joints. Pain Physician 3(2), 158-166.

McCormick, Z. L., Walker, J., Marshall, B., McCarthy, R., Walega, D. R. (2014) A novel modality for facet joint denervation: Cooled radiofrequency ablation for lumbar facet syndrome. A case series. Phys. Med. Rehabil. Int. 1(5), 5.

Nagi, S. Z. (1976) An epidemiology of disability among adults in the United States. Milbank Mem. Fund Q. Health Soc. 54(4), 439-467.

Schwarzer, A. C., Aprill, C. N., Derby, R., Fortin, J., Kine, G., Bogduk, N. (1994) The relative contributions of the disc and zygapophyseal joint in chronic low back pain. Spine (Phila. Pa 1976) 19(7), 801-806.

Shabat, S., Leitner, Y., Bartal, G., Folman, Y. (2013) Radiofrequency treatment has a beneficial role in reducing low back pain due to facet syndrome in octogenarians or older. Clin. Interv. Aging 8, 737-740.

Stranjalis, G., Tsamandouraki, K., Sakas, D. E., Alamanos, Y. (2004) Low back pain in a representative sample of Greek population analysis according to personal and socioeconomic characteristics. Spine (Phila. Pa 1976) 29(12), 1355-1360.

Tekin, I., Mirzai, H., Ok, G., Erbuyun, K., Vatansever, D. (2007) Comparison of conventional and pulsed radiofrequency denervation in the treatment of chronic facet joint pain. Clin. J. Pain 23(6), 524-529.

Vatansever, D., Tekin, I., Tuglu, I., Erbuyun, K., Ok, G. (2008) A comparison of the neuroablative effects of conventional and pulsed radiofrequency techniques. Clin. J. Pain 24(8), 717-724. 